\title{
Absence of nystagmus during REM sleep in a patient with waking nystagmus and oscillopsia ${ }^{1}$
}

\author{
EDWARD S. TAUBER, ELLIOT D. WEITZMAN, JOHN HERMAN, AND \\ MICHAEL PESSAH
}

\author{
From the Department of Neurology, Montefiore Hospital, and Medical Center, \\ Albert Einstein College of Medicine, Bronx, New York, U.S.A.
}

SUMMARY Polygraphic recording is presented of the sleep pattern in a young male who developed nystagmus and oscillopsia associated with a remittent CNS demyelinating disease. The vestibular nystagmus observed during wakefulness disappeared during all stages of sleep, including rapid eye movement sleep (REM). Since vestibular nystagmus experimentally induced in wakefulness is also absent during all phases of sleep, these findings suggest that during sleep similar suppressive mechanisms are operative.

There is increasing evidence that the organization of eye movements in man during both rapid eye movement (REM) and non-REM sleep, differs from the patterns observed and recorded during wakefulness. Specific differences have been reported with respect to angular velocity and the distribution and sequencing of the direction of conjugate gaze movements (Jacobs, Feldman, and Bender, 1971, a, b).

The effects of the sleep-wakefulness cycle on the various forms of nystagmus in man have received less attention. Gardner and Weitzman (1967) noted that optokinetic stimulation elicited no nystagmic reaction during any stage of sleep. Furthermore, the literature reveals that neither post-rotatory nor per-rotatory vestibular stimulation will elicit nystagmus during any stage of slow wave sleep (DiGiorgio, 1935; Keser, 1947; Jung and Kornhuber, 1964; Reding and Fernández, 1968; Jones and Sugie, 1972; Tauber, Handelman, Handelman, and Weitzman, 1972). Reding et al. (1968) employing per-rotatory vestibular stimulation at 10 minute intervals during sleep in a sample of five children reported that 'depressed nystagmus was significantly associated with the occurrence of the rapid eye movements of sleep.' More recently, Tauber et al.

${ }_{1}$ Supported in part by funds from Grant No. EC-00341 and NASA Contract No. 9-BB32-79-2-1461. Presented at the 12th Annual Meeting of the Association for the Psychophysiological Study of Sleep, New York, May 1972.
(1972) studied the effects of vestibular stimulation (torsion swing: per-rotatory technique) during REM sleep in young adults and observed no nystagmus response. Perachio (1972) studying the effects of vestibular stimulation on the sleep pattern of the simian primate Aotus trivirgatus employed continuous rotation at a constant velocity of $12 \mathrm{rpm}$ for six to seven days. $\mathrm{He}$ reported the presence of vestibular nystagmus during active wakefulness (no habituation) but observed no evidence of nystagmus during any phase of sleep.

In a study of endogenously induced nystagmus during sleep, Arkin, Weitzman, and Hastey (1966) reported that all night recordings of five subjects with congenital nystagmus manifesting clear-cut nystagmus during wakefulness nevertheless revealed no evidence of a nystagmic response during any of the sleep stages. In a subsequent replication of that study Arkin, Lutzky, and Toth (1972) confirmed their previous results. They noted again that brief episodes of reduced amplitude nystagmus jerks were occasionally observed during the REM periods, adding that such oscillations have been observed in the records of normal subjects. This latter finding had also'been reported by Dement (1964).

Baldissera, Broggi, and Mancia (1967) and Lenzi and Pompeiano (1970) studied the effects of unilateral labyrinthectomy and unilateral 
L.EYE - R.EAR

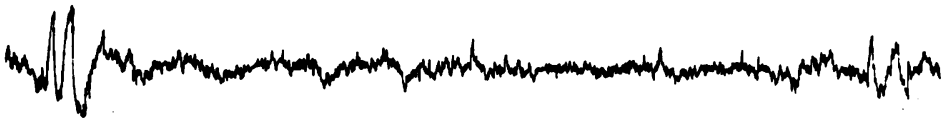

R.EYE - R.EAR

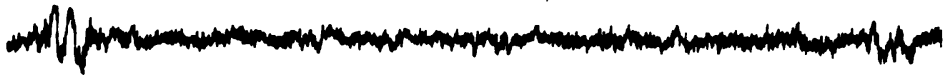

L.EYE - R. EYE (HORIZ.)

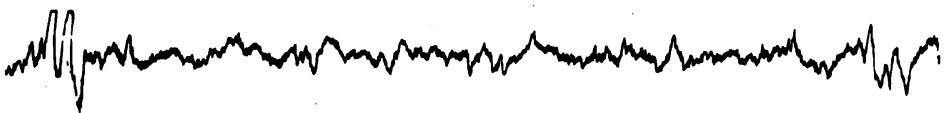

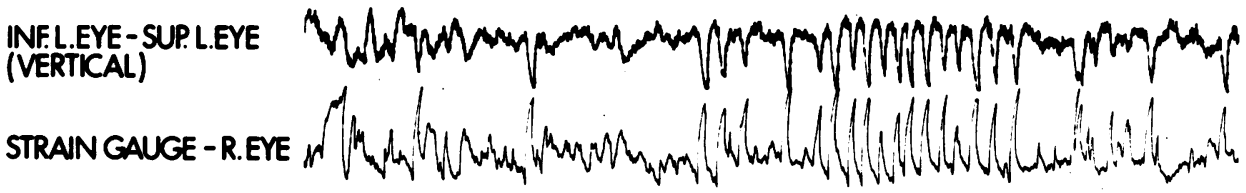
EMG CHIN-CHEEK

$C_{3}-R . E A R$

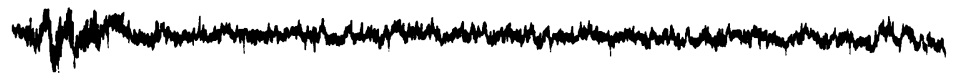

$C_{4}-$ R. EAR

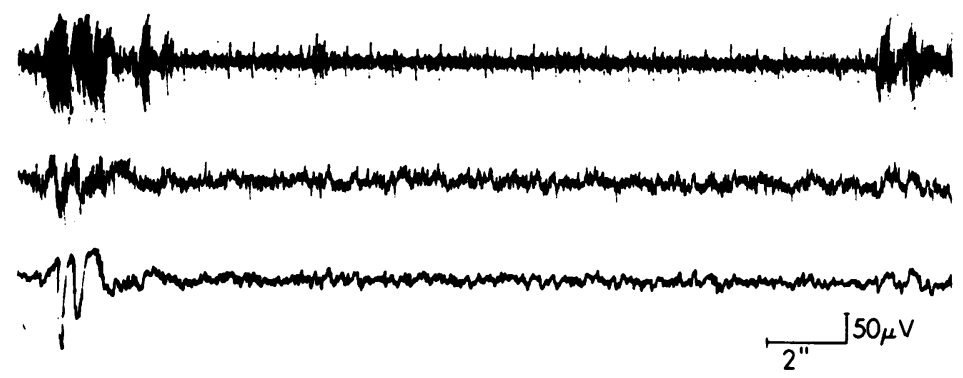

FIG. 1. Polygraphic recording of nystagmus during waking state.

L.EYE - R.EAR

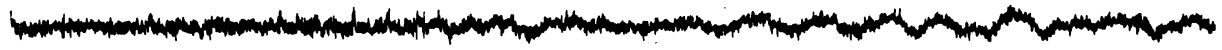

R.EYE - R.EAR

(HOYE -R. EYE
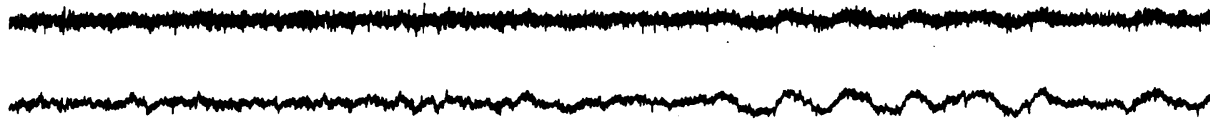

INFL.EYE - SUP. L.EYE (VERTICAL)

\section{r}

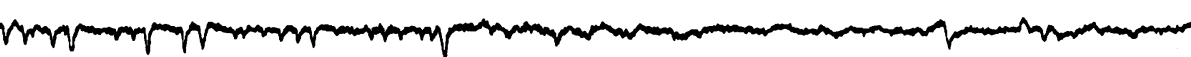
STRAIN GAUCE - REYE
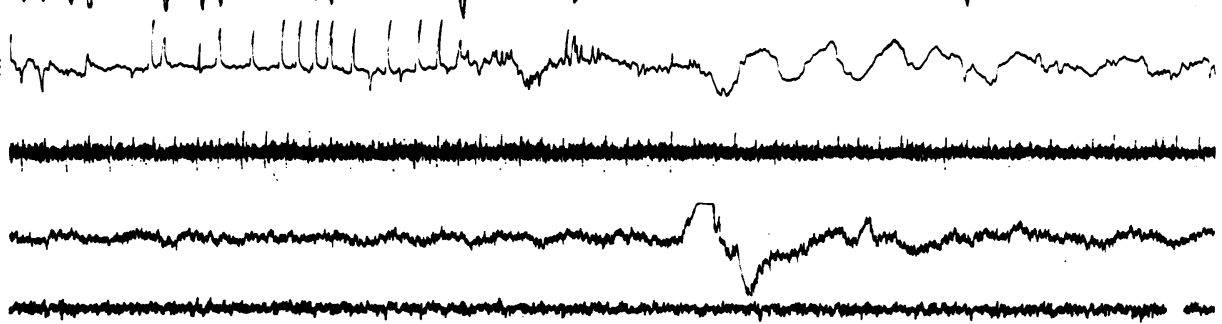

$C_{4}$-R. EAR

FIG. 2. Polygraphic recording demonstrating transition from waking to stage I sleep. 
L.EYE - R. EAR

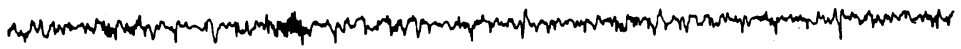

R.EYE - R.EAR

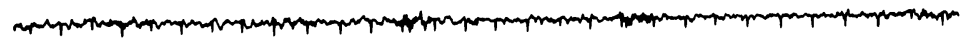

L.EYE -R.EYE

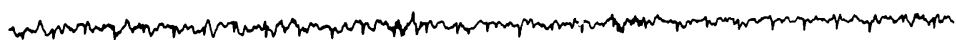
(HORIZ.)

INF. L.EYE - SUP. L.EYE (VERTICAL)

STRAIN GAUGE - R. EYE

EMG CHIN - CHEEK

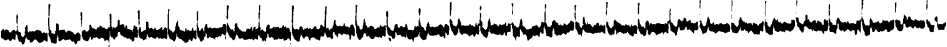

$C_{3}$ - R.EAR

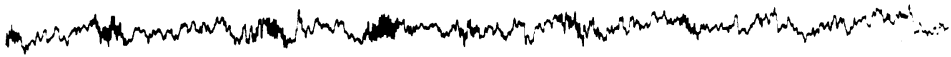

$C_{4}-$ R.EAR

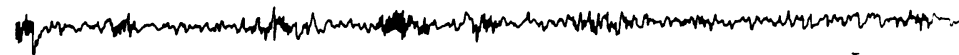
$2^{\prime \prime} 550 \mu \mathrm{V}$

FIG. 3. Polygraphic recording-stage II sleep. No nystagmus can be recognized.

L.EYE - R.EAR

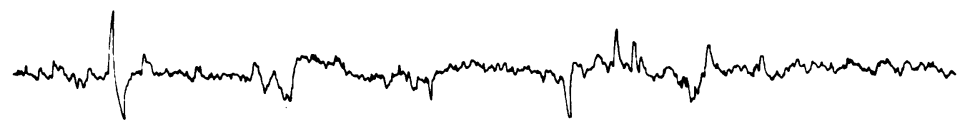

R.EYE - R.EAR

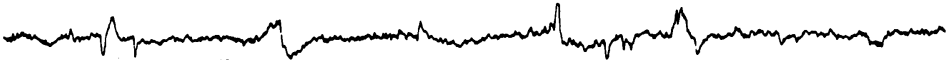

L.EYE - R. EYE

(HORIZ.)

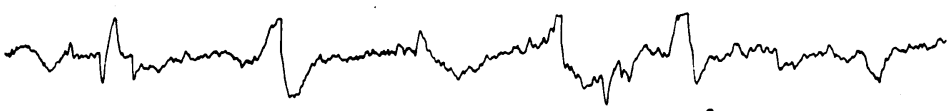

INF.L.EYE-SUP.L.EYE (VERTICAL)

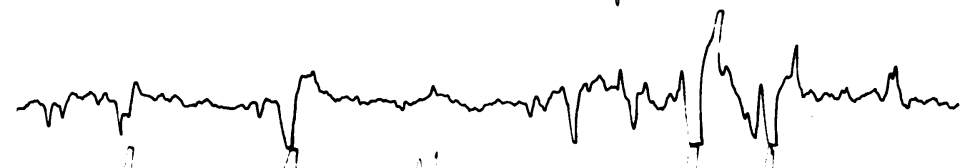

STRAIN GAUGE - R.EYE

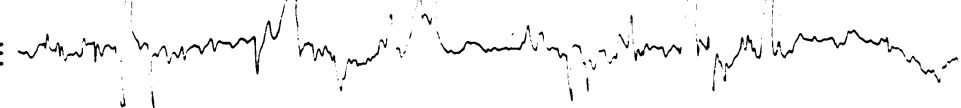

EMG CHIN-CHEEK

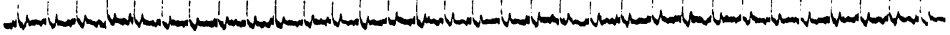

$C_{3}-$ R. EAR

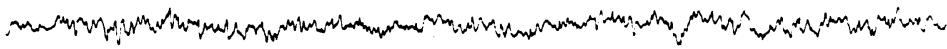

$C_{4}-$ R.EAR

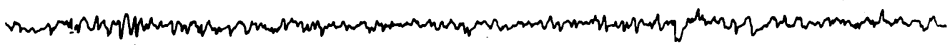

FIG. 4. Polygraphic recording in stage REM sleep-rapid eye movements are present without evidence of nystagmus. 
L.EYE - R.EAR

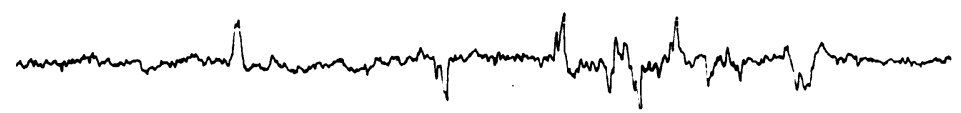

R.EYE - R.EAR

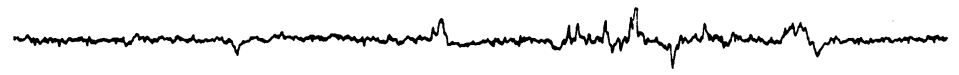

L.EYE - R.EYE

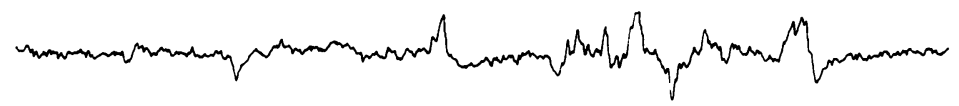

INF.L.EYE-SUP. L.EYE
(VERTICAL)

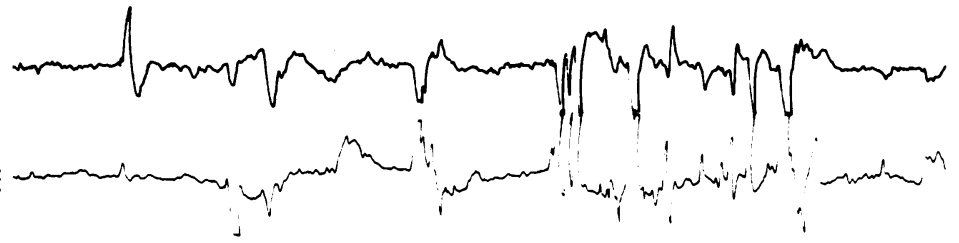

EMG CHIN-CHEEK
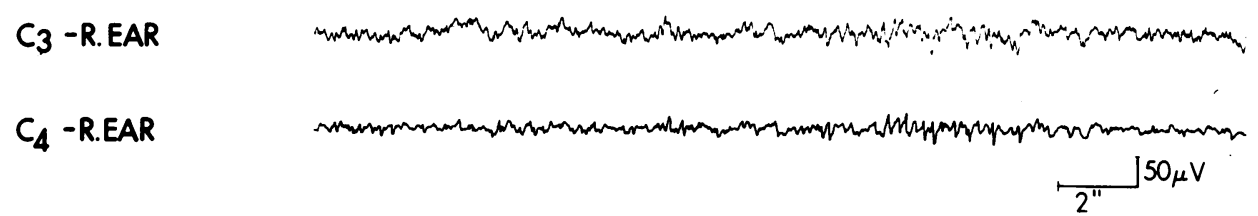

FIG. 5. Polygraphic recording in stage REM sleep_rare nystagmus-like oscillations present on vertical eye movement and strain gauge channels.

section of the VIIIth nerve respectively, during the sleep-wakefulness cycle of the cat. Nystagmus was unequivocally present for several days postoperatively during wakefulness. However, with the advent of 'spindling' in the electroencephalogram (EEG), slow wave as well as REM sleep, the nystagmic response was severely depressed or completely abolished. Occasional nystagmus-like oscillations accompanied the rapid eye movements of desynchronized sleep but these oscillations were of very short duration and were clearly different from the long trains of well-defined nystagmus noted during wakefulness. In contrast with the above findings in man and the cat, Appenzeller and Fischer (1968) reported that in patients with neurological disease, nystagmus was found to accompany rapid eye movements during sleep if it was present when the patient was awake.

Since the inventory of studies reporting the persistence or emergence of neurological abnormalities during sleep is limited, we considered it important to report on the eye movement patterns during sleep of a young male adult who developed oscillopsia in association with vertical and rotatory nystagmus due to pathology of the central nervous system secondary to a remittent demyelinating disease. Specifically the question is raised as to whether the endogenously evoked nystagmus observed during wakefulness would persist during sleep or emerge in any of its stages. This question is also part of the broader issue of defining the effects of the sleep-wakefulness cycle on the persistence or suppression of different types of neurological abnormalities. Thus 3 Lugaresi, Coccagno, Mantovani, Berti Ceroni, 8 Pazzaglia, and Tassinari (1970) have reported $₹$ that certain types of myoclonus are present 9 throughout sleep, while other types disappear in $>$ sleep. Tassinari, Broughton, Poiré, Roger, and Gastaut (1965) have noted that Parkinsonian No tremor and choreoathetoid movements disappear during sleep, while Poppi, Pazzaglia, Coccagna, 옹 Berti Ceroni, and Lugaresi (1966) have found 
that tonic-clonic facial spasms and the fasciculations in amyotrophic lateral sclerosis persist throughout sleep.

\section{CASE HISTORY AND RESULTS}

The patient is a 27 year old male who had a one year history indicative of a diffuse demyelinating disease. On 14 December 1971, he noted the rapid development of oscillopsia which increased during each day and was present upon awakening. The oscillopsia progressed over several days. On awakening each morning, it would take between 10 to 15 minutes before the oscillopsia would again be present. $\mathrm{He}$ had nystagmus on forward gaze with a major vertical component present in both eyes. Nystagmus was present on lateral gaze but less than on vertical gaze. He denied double vision and had no change in visual acuity. There were no other new neurological findings. The vertical oscillopsia persisted for a period of approximately eight days. On the fourth day the patient was studied with an all-night polygraphic recording.

Before the patient's usual time of sleep, electrodes were applied at standard positions for recording EEG, and chin electromyogram (EMG). The electrooculographic recording was obtained from electrodes (Ag-AgCl) placed lateral to each orbit, superior and inferior to the right eye. A strain gauge (Kulite-Semiconductor) applied to the lid of the left eye recorded small eye movements. Polygraphic AC-recording in the awake state with the eyes open and closed, in a well-lit, as well as in a dark room, demonstrated the continuous presence of clearly recordable vertical nystagmus in both eyes independent of direction of gaze or head position (Fig. 1).

The nystagmus with lights on and eyes open had a fairly regular quality during the waking state, with intervals between beats varying between 250 and $600 \mathrm{msec}$. The angular travel of the oscillopsia was estimated at 1 to $2^{\circ}$. The waking frequency of the nystagmus was approximately 150 per minute. After lights were out with eyes closed for 10 minutes, the nystagmic movements, although still clearly detectable, displayed a markedly decreased frequency with periods preceding sleep in which nystagmus was completely absent. During this period the subject was awake by EEG criteria, although waking rapid eye movements had ceased (Fig. 2).

The nocturnal sleep pattern was characterized by three rapid eye movement (REM) periods lasting 14,14 , and 52 minutes, respectively. Total sleep time was 302 minutes: 28 minutes were spent in stage 1 , 194 minutes in stage 2, and he had no stage 3 and 4 .

In the minute before sleep onset, nine small eye movements were present and these were not similar in form to the previous nystagmus. In the two minutes after sleep onset no eye movements were present, although nystagmus returned subsequently, superimposed upon a slow eye movement pattern for a period of five minutes. During this time the subject was in stage 1 sleep. With the advent of stage 2 spindles in the EEG, nystagmoid movements completely subsided (Fig. 3). During stage 2 sleep there were infrequent-that is, less than one per minute-indications of ocular activity on the strain gauge channel which were not present on the electrooculogram (EOG) leads. However, at times during low voltage stage 2 sleep, there were intermittent rare indications of strain gauge activity that appeared nystagmus-like. During REM sleep nystagmus was absent (Fig. 4). On two or three occasions despite the presence of normal eye movements nystagmoid activity was present lasting five to 10 seconds. These were associated with normal REMs (Fig. 5).

It is interesting to note that when nystagmus returned after a spontaneous awakening at night, it was not clearly present until one minute after the patient awoke. It was then present intermittently with intervals of up to one minute when nystagmus was absent. It should be emphasized that the nystagmus during this waking interval did not resemble the quite regular, pulse-like, rapid beat that was continuously present in the daytime waking state.

At the termination of sleep in the morning, the polygraphic pattern, as well as clinical evidence of vertical nystagmus, promptly reappeared. Within a few minutes the patient again had the subjective symptom of vertical oscillopsia.

In a follow-up study several weeks later when the syndrome was in remission, an all night electrographic study revealed no evidence of trains of nystagmic oscillations during wakefulness. Occasional brief nystagmoid jerks accompanied the rapid eye movements of REM sleep.

\section{CONCLUSION}

With certain exceptions noted in this article, the literature indicates that the nystagmic response during all phases of sleep whether elicited by optokinetic or by vestibular stimulation is either profoundly depressed or completely abolished in man and the owl monkey (Aotus trivirgatus). Endogenously induced vestibular nystagmus is also absent in patients with congenital nystagmus during all stages of sleep. This is also true for cats after unilateral labyrinthectomy and unilateral section of the VIIIth nerve. However, a nystagmic response was reported to be present 
during REM sleep in those patients with neurological disease where nystagmus occurred during wakefulness (Baldissera et al., 1967). In contrast, our findings indicated that nystagmic oscillations are of low amplitude, infrequent, and of short duration during REM sleep and are in no way similar to the trains of nystagmic oscillations during wakefulness. On the basis of these data, we suggest that a significant difference exists between the nystagmus of wakefulness and the eye movement patterns of REM sleep. Since vestibular stimulation in normal subjects also fails to produce nystagmus during any stage of sleep, including REM sleep, we suspect that a similar mechanism may be operative to suppress the endogenous nystagmus in patients with disease of the central nervous system. It would be of interest to study nystagmus in other forms of neurological disease in which the specific pathological anatomy was known. The present findings continue to support the evidence that mechanisms in the central nervous system initiating nystagmus have a different organization of control during all sleep stages from that which takes place during wakefulness.

\section{REFERENCES}

Appenzeller, O., and Fischer, A. P., Jr. (1968). Disturbances of rapid eye movements during sleep in patients with lesions of the nervous system. Electroencephalography and Clinical Neurophysiology, 25, 29-35.

Arkin, A. M., Weitzman, E. D., and Hastey, J. M. (1966). An observational note on eye movement patterns during REM and non-REM sleep in subjects with congenital nystagmus. Psychophysiology, 3, 69-72.

Arkin, A. M., Lutzky, H., and Toth, M. F. (1972). Congenital nystagmus and sleep: a replication. Psychophysiology, 9, 210-217.

Baldissera, F., Broggi, G., and Mancia, M. (1967). Nystagmus induced by unilateral labyrinthectomy affected by sleepwakefulness cycle. Nature, 215, 62-63.
Dement, W. C. (1964). Eye movements during sleep. In Th⿻ Oculomotor System, pp. 366-416. Harper and Row: Ne荒 York.

Di Giorgio, A. M. (1935). Comportamento di alcune reazionf labirintiche durante il sonno fisiologico. (Ricerche nei banf bini.) Bollettino della Società Italiana di Biologia Sperī̄on mentale, 10, 951-953.

Gardner, R., and Weitzman, E. D. (1967). Examination fof optokinetic nystagmus in sleep and waking. Archives $\overline{0 .}$. Neurology, 16, 415-420.

Jacobs, L., Feldman, M., and Bender, M. B. (1971a). Eye: movements during sleep. 1. The pattern in the norma委 human. Archives of Neurology, 25, 151-159.

Jacobs, L., Feldman, M., and Bender, M. B. (1971b). Ey? movements during sleep. 2. The pattern with upward gaz paralysis. Archives of Neurology, 25, 212-217.

Jones, G. M., and Sugie, N. (1972). Vestibulo-ocular re sponses in man during sleep. Electroencephalography an\& Clinical Neurophysiology, 32, 43-53.

Jung, R., and Kornhuber, H. H. (1964). Results of electro nystagmography in man: the value of optokinetic, vestibu? lar, and spontaneous nystagmus for neurologic diagnosis and research. In The Oculomotor System, pp. 428-488c Edited by M. B. Bender. Harper and Row: New York.

Keser, H. (1947). Variationen des Drehnystagmus beim Gesun den nach der Amplitudenauswertung. In Bericht Kongreso für Neurologie und Psychiatrie (Tubingen), pp. 239-243.

Lenzi, G. L., and Pompeiano, O. (1970). Orthodromic trans? mission of 8th nerve volleys through the vestibular nuquef during sleep. Advances in Oto-Rhino-Laryngology, 17, 2-37ట్ట

Lugaresi, E., Coccagna, G., Mantovani, M., Berti Ceroni, Pazzaglia, P., and Tassinari, C. A. (1970). The evolution of different types of myoclonus during sleep. A polygraphic study. European Neurology, 4, 321-331.

Perachio, A. A. (1972). Vestibular influence on sleep in nơne human primates. Eleventh Annual Meeting of the Aso ciation for the Psychophysiological Study of Sleep. SE्E Research, Vol. I. Brain Information Service/Brain Research Institute, UCLA. Los Angeles.

Poppi, M., Pazzaglia, P., Coccagna, G., Berti Ceroni, 宁. and Lugaresi, E. (1966). Iperinesie patologiche persistent $\mathrm{W}$ durante il sonno. Rivista di Neurologia, 36, 624-633.

Reding, G. R., and Fernández, C. (1968). Effects of vestibulars stimulation during sleep. Electroencephalography and Clinical Neurophysiology, 24, 75-79.

Tassinari, C. A., Broughton, R., Poiré, R., Roger, J., andڤ̆ Gastaut, H. (1965). Sur l'evolution des mouvements anor- $\bar{Q}$ maux au cours du sommeil. In Le Sommeil de Nuit Norma et Pathologique, p. 314. Masson: Paris.

Tauber, E. S., Handelman, G., Handelman, R., and Weitz-3 man, E. D. (1972). Vestibular stimulation during sleep in young adults. Archives of Neurology, 27, 221-228. 